\title{
Scientists decry Canada's outdated Wi-Fi safety rules
}

$\mathrm{F}$ Tederal parliamentarians concluded three hearings into Health Canada's safety regulations for cellphones and other wireless devices by asking for a detailed analysis of numerous recent cancer studies that indicate far tougher safety regulations may be warranted.

The studies in question were not acknowledged in the scientific review, Safety Code 6 (2015) - Rationale, exclusively released to CMAJ by Health Canada. The Safety Code 6 guideline, which was released Mar. 13, states that no new biological information pertinent to safety guidelines has emerged since 2009. Further, it states that the large number of recent studies raising safety concerns "suffer from a lack of evidence of causality, biological plausibility and reproducibility and do not provide a credible foundation for making science-based recommendations."

This contention led scientists and safety advocates at the hearings before Parliament's Standing Committee on Health to mount a withering attack, saying that Health Canada's Rationale and Safety Code 6 are outdated, incomplete and invalid.

As a result, at the conclusion of the hearings on Apr. 30, the Standing Committee on Health asked Health Canada to "provide detailed information in the form of a full scientific monograph" on its assessment of 140 studies identified as alarming by Canadians for Safe Technology, an Oakville, Ontariobased advocacy group.

The group's CEO, Frank Clegg, told the health committee on Apr. 23 that despite paying the Royal Society of Canada $\$ 100000$ to convene a panel to assess the safety of radiowave-emitting devices (a panel that was subsequently marred by conflict-of-interest allegations and the resignation of its chairman) "Health Canada has not invested the necessary time, nor had the balanced opinion of experts necessary to undertake a proper review."

After noting that health regulators

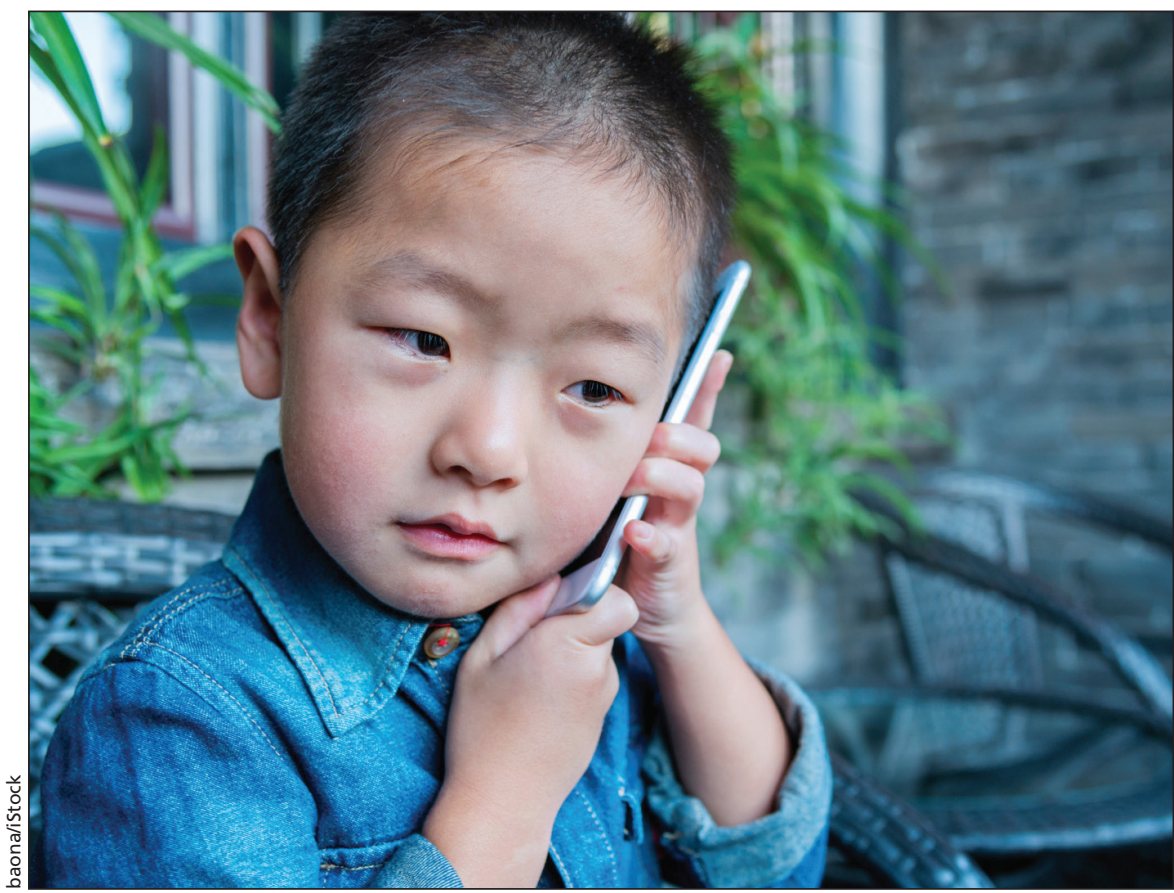

Scientists and safety advocates say Health Canada's new rules do not take into account many new studies on the safety of cellphones and other wireless devices.

failed to forestall public health disasters with tobacco, asbestos, bisphenol A, thalidomide, DDT and urea formaldehyde insulation, Clegg said "prudent avoidance" should be recommended with cellphones and Wi-Fi "until the science proves beyond reasonable doubt that there is no potential for harm. For the last three years science has published a new study every month that shows irreparable harm at levels below Safety Code 6."

Clegg told the health committee that China and Russia have guidelines 100 times safer than Health Canada's Safety Code 6. "Canada should be among progressive countries such as France, Belgium and Taiwan that have laws in place to protect children in the home and at school or daycare centres," Clegg says.

"A proper scientific evaluation would clearly show that Health Canada is not taking the appropriate action to safeguard the health of Canadians."

Clegg's comments echo those of Terence Young, the Conservative MP for Oakville, Ont., who has a record of successfully proposing and passing health safety legislation. In January, Young tabled a private member's bill that would require manufacturers to place clearly visible safety warnings on all cellphones, cordless phones and radio frequency-emitting devices such as Wi-Fi transmitters.

In an intense confrontation at the health committee meeting, Young demanded that Health Canada explain its methodologies for rejecting evidence from a series of recently published studies by Swedish researcher Dr. Lennart Hardell. In his most recent study, Hardell concluded "that glioma and also acoustic neuroma are caused by RFEMF emissions from wireless phones, and thus regarded as carcinogenic ... indicating that current guidelines for exposure should be urgently revised" (Pathophysiology 2015;22:1-13).

James McNamee, chief, Health Effects and Assessments Division, at Health Canada's Healthy Environments and Consumer Safety Branch, who is the Rationale's principal author, responded to Young's inquiry. He said 
the department's evaluation principally relied on a scientific review completed in May 2011 by the World Health Organization's International Agency for Research on Cancer (IARC), which concluded that cellphones and other wireless devices such as cordless phones and Wi-Fi transmitters are possibly although not probably - carcinogenic.

"We're subject to the evidence base we have at this time," said McNamee, who coauthored two scientific reviews with scientists who have acknowledged accepting payments from industry and government in return for promoting
Hardell agrees. After reviewing the Rationale, Hardell described Health Canada's safety guidelines in an interview with $C M A J$ as "a disaster to public health" and based on a scientific analysis "unwilling or not competent to make evaluation of the current literature."

Miller says the Rationale overlooks numerous other important studies as well as Hardell's, including a recent study by Gaëlle Coureau, of Université Bordeaux Segalen, which concluded that it supports "previous findings concerning a possible association between heavy mobile phone use and brain

\section{One expert says the guidelines are "a disaster to public health"}

industry and government safety assurances ( $J$ Toxicol Environ Health B 200912:2004-7; Int J Radiat Biol 2005 81:189-203).

McNamee's reliance on the studies included in the IARC's four-year-old review as still the most pertinent evidence available was subsequently called into question during the health committee hearings by one of the IARC review's own authors.

Dr. Anthony Miller, a University of Toronto professor emeritus who served as scientific secretary for the IARC panel, says Hardell's new research "reinforces the evidence that radio frequency fields are not just a possible human carcinogen, but a probable human carcinogen."

Hardell's studies, Miller told the committee members, "would be impossible to ignore in regulatory approaches to such a hazard" had Health Canada carefully considered them. tumours" (Occup Environ Med 2014;71: 514-22).

After reviewing the Rationale, Coureau told CMAJ its analysis of the epidemiological literature did not warrant discussion.

Hardell and Coureau are not the only authors of recent studies raising concerns about cellphone safety who take issue with McNamee's Rationale and Safety Code 6.

At McGill University in Montréal, Paul Héroux, author of a recent paper indicating extra-low-frequency magnetic fields alter cancer cells through metabolic restriction, describes the Rationale as a document that deliberately ignores all studies that call Safety Code 6 into question (Electromagn Biol Med 2014;33:264-75). "The soul of science is to revise health protection when evidence undermines previous thinking and this review fails to do that."
At Washington University in Seattle, Henry Lai, author of numerous studies indicating radiofrequency exposure appears to affect DNA damage and repair, described the Rationale to CMAJ as "simplistic and out-ofdate" with "too much focus on dosimetry and theoretical calculations, at the expense of basic concepts of biology and health"

The Rationale, Lai adds "fails to take into account at least a couple of hundred papers published between 2009 and 2014 on the biological effects of radiofrequency radiation, such as changes in cellular and reproductive functions. Many of these studies show effects at exposure levels much lower than the [Safety Code 6] limits."

Although CMAJ was invited by Health Canada to interview McNamee before he testified to the committee, the invitation was withdrawn without explanation after he testified. In response to written questions submitted to McNamee by $C M A J$, Health Canada emailed a statement on Apr. 30 explaining that "Departmental scientists considered all available peer-reviewed scientific studies when developing the exposure limits in the revised Safety Code 6."

Their review "employed a weight-ofevidence approach when evaluating possible health risks," the Department explained, while acknowledging it has elected not to publish McNamee's Rationale on its website devoted to Safety Code 6. "Health Canada's updated Safety Code 6 makes Canada's limits among the most stringent science-based limits in the world," it added. - Paul Christopher Webster, Toronto, Ont.

CMAJ 2015. DOI:10.1503/cmaj.109-5061

\section{Dr. David Sackett, a giant among giants (1934-2015)}

$\mathrm{O}$ $\mathrm{n}$ his first day of medical school, Philip Devereaux learned from a tutor that his academic advisor was Dr. David Sackett. "Who is he?" Devereaux recalls asking. The tutor told him that Sackett was a famous clinical epidemiologist. But Devereaux had no interest in clinical epidemiology; he planned on returning home to Cape Breton and being a "real" doctor.

"My first thought was: how am I going to get rid of this guy and get a real advisor?" said Devereaux.

Then he met Sackett. And like so many other young physicians and researchers, his life was soon set on a whole new path. "He opened up my eyes to a world I didn't even know existed," said Devereaux, now an assistant professor in the department of clinical epidemiology and biostatistics at McMaster University, a department founded by Sackett in 1967. "He was a giant among giants."

Sackett, a pioneer in clinical epidemiology, died at age 80 on May 13. His 